\title{
A construção da solidariedade na escola: as virtudes, a razão e a afetividade
}

\author{
Luciene Regina Paulino Tognetta \\ Orly Zucatto Mantovani de Assis \\ Universidade Estadual de Campinas
}

\section{Resumo}

Discutindo sobre como as pessoas podem construir a solidariedade, baseando-se em pressupostos psicológicos que garantem que tal virtude é construída por cada um na interação com o meio, esta pesquisa aponta um caminho para a formação de sujeitos mais autônomos e solidários: a cooperação como estratégia de conceber a construção das virtudes.

Para tal, foram investigados, em comparação, os julgamentos de crianças de ambos os sexos, na faixa etária de 6 a 7 anos, provenientes de dois tipos de ambientes: $A$ - baseado em relações autoritárias; e B - em relações de cooperação. Utilizou-se da aplicação das provas de diagnóstico do comportamento operatório de Jean Piaget, no intuito de verificar um paralelo entre as estruturas cognitivas e morais dos sujeitos, como também da observação das relações interpessoais e da discussão de dilemas morais, divididos em dois blocos, que atenderam a dois requisitos desta investigação: constatar o julgamento da solidariedade entre pares e na presença da autoridade.

Os resultados demonstram a existência de uma evolução na disposição dos sujeitos para serem solidários, ligada a uma perspectiva de vivenciarem experiências significativas de reciprocidade e respeito mútuo, características de um ambiente cooperativo. Tais resultados nos permitem conceber uma "Pedagogia das virtudes", que considere o desenvolvimento das estruturas cognitivas e dos aspectos afetivos para a construção de personalidades morais.

\section{Palavras-chave}

Solidariedade - Virtudes - Razão - Afetividade.

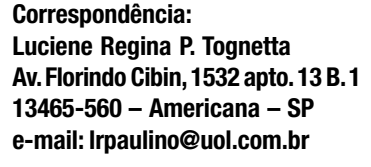




\title{
The construction of solidarity at school: the virtues, the reason, and the affectivity
}

\author{
Luciene Regina Paulino Tognetta \\ Orly Zucatto Mantovani de Assis \\ Universidade Estadual de Campinas
}

\begin{abstract}
Discussing how people can build up solidarity, and drawing from psychological assumptions that guarantee that such virtue is constructed by each one in their interaction with the environment, this research points to a path for the formation of more autonomous and solidary subjects: the cooperation as a strategy to conceive the construction of virtues.

To this end, a comparative investigation was made of the judgments of children of both sexes, aged 6 and 7 , in two kinds of environments: $A$ - based on authoritarian relations; and B - in relationships of cooperation. Diagnostic tests for Jean Piaget's operatory behavior were used to investigate the parallel between the cognitive and moral structures of the subjects. The study also used the observation of the interpersonal relationships and the discussion of moral dilemmas split into two groups, and which fulfilled two conditions: to inspect the judgment of solidarity between peers, and in the presence of authority.

Results demonstrate the existence of an evolution in the disposition of the subjects to be solidary, linked to the prospect of significant experiences of solidarity and mutual respect, characteristic of a cooperative environment. Such results allow us to envisage a "Pedagogy of Virtues" that takes in the development of cognitive structures and affective aspects to the construction of moral personalities.
\end{abstract}

\section{Keywords}

Solidarity - Virtues - Reason - Affectivity.

Contact:

Luciene Regina P. Tognetta

Av. Florindo Cibin, 1532 apto. 13 B. 1

13465-560 - Americana - SP

e-mail: Irpaulino@uol.com.br 
Por que as ações das pessoas nem sempre são morais? Essa indagação se faz presente a todo tempo, em diversos lugares do mundo, para situações que não retratam apenas cenas de violência e descumprimento do que acreditamos serem deveres como o respeito e a justiça, mas também do que podemos chamar de princípios que garantem uma vida em comum: a honestidade, a solidariedade, a humildade. Essas e tantas outras virtudes parecem tomar um lugar especial em discussões sobre a moralidade em tempos atuais. Porém, como uma dicotomia, tal discussão já se fazia presente desde há muito tempo na história das relações humanas. É fato que só discutimos a moral por sua falta.

Poderiamos aqui elencar mais uma questão, esta um pouco mais cotidiana: por que os alunos das mais variadas escolas não resolvem seus problemas sem usar de violência, se todo dia é lembrado a eles que não se podem bater uns nos outros? De onde virá essa preocupação que assola o tempo de tantos profissionais de educação? Talvez venha do desejo de realizar seus objetivos traçados em planos escolares, de ver a solidariedade, a humildade, o respeito, a justiça e o diálogo construídos por seus alunos.

Digamos que temos, então, duas questões distintas: a primeira corresponde a um macrossistema de relações de certa forma planetárias e a segunda indagação correspondente àquela microssociedade que traduz a sala de aula. Porém, essas duas questões nos permitem compreender com clareza uma necessidade humana: repensar a moral e, sobretudo, rever as formas de intolerância, de desrespeito ao outro, que constatamos estampadas em nosso cotidiano.

$\mathrm{Na}$ verdade, ao elucidarmos a primeira de nossas questões, não temos a pretensão de esgotar todas as discussões que poderiam ser feitas, mesmo porque os conflitos que destacamos têm dimensões culturais, políticas e ideológicas que precisam ser consideradas para uma análise mais aprofundada de suas causas. Dessa forma, apenas desejamos, a partir dessas questões, tornar possível uma reflexão sobre a moral e, se quisermos, sobre a formação de pessoas virtuosas, pois a necessidade desses estudos se faz presente desde pequenos "atentados" cotidianos entre nossas crianças até seu extremo, aos atentados à vida humana.

0 que será preciso fazer para que aqueles valores morais por nós desejados sejam colocados em prática?

Pensemos, portanto, seguindo os passos da Psicologia Moral, em como um valor ou uma virtude como a solidariedade ou tantas outras podem ser construídas.

Nesse sentido, voltemos ao modelo psicológico piagetiano, que nos permite pensar a moral em termos de evolução, ainda que tenda a ligar tal sistema conceptual ao desenvolvimento das estruturas cognitivas. A partir dele, elucidaremos como a pedagogia pode dar conta da formação de nossas crianças, considerando ainda a dimensão afetiva de sua evolução.

Piaget se refere a duas tendências morais que determinam os julgamentos humanos e as compreende como um contínuo desenvolvimento. Em seus estudos, considera a moral como um sistema de regras que se constrói na interação do sujeito e suas estruturas internas com o objeto. Considera que as pessoas nascem com uma ausência total de regras e é exatamente essa interação com o meio físico e social que permitirá sua construção pelo sujeito. Um bebê aprende logo nos primeiros segundos de vida, fora do útero materno, a respirar, utilizando os pulmões e as vias respiratórias que antes, embora já existentes, não eram utilizadas por ele. 0 meio impõe e cria a regra de sobrevivência.

A criança pequena não distingue o que pode ou não fazer. Descobre o mundo pela ação física, pelo movimento, pelas sensações. Quem a livra dos perigos, quem a alimenta e troca sua roupa é o adulto. Por tais motivos, vai considerá-lo, não obstante, como aquele que tudo sabe, que tudo pode. Porém, ao mesmo tempo, tentando constituir-se como ser separado de sua mãe, como único, revela uma característica comum e própria de uma tendên- 
cia moral que irá prevalecer por algum tempo (ou muito, em tantos casos!). Tal característica, que o faz centrar-se em apenas uma possibilidade de resolver seus conflitos, caracteriza o egocentrismo. Com seu "Eu", centrado em si mesmo, esse sujeito não é capaz de reconhecer o ponto de vista do outro, de resolver os conflitos que se apresentam em sua relação com os demais (Piaget, 1931).

Por seu pensamento pré-lógico, esse sujeito não é capaz de pensar em mais de uma possibilidade para resolver seus problemas. A tal conduta, Piaget (1994) chamou heteronomia. É característica dessa fase que as regras sejam exteriores ao sujeito. Também chamada por ele de "moral da obediência”, os sujeitos acreditam que a obediência deva prevalecer, pois não há legitimação, por sua parte, das regras que the são impostas.

Uma moral heterônoma não compreende diferenças e pensamentos divergentes, não contrapõe pontos de vista; nela, permanece adormecida qualquer experiência de contrato. Por isso, chamamo-la também de moral não contratual.

Digamos que é objetivo daqueles que educam que todos os sujeitos superem essa tendência e cheguem a uma "moral do bem", como prescrevia Piaget. Nela, os pontos de vista podem ser coordenados, porque acompanham uma evolução cognitiva que garante ao sujeito uma capacidade de operar, coordenar ações que podem ser reversíveis, ir e vir em plano de pensamento. Torna-se possível constatar diferenças, os pontos de vista dos outros, coordená-los com os seus próprios e legitimar as regras como contratos.

Tomamos um certo cuidado ao tratarmos dos termos citados como "moral da obediência" para a heteronomia e "moral do bem" para a autonomia, no sentido de não se chegar a conclusões equivocadas como a de que na heteronomia há a obediência e na autonomia não há. Esse foi um equívoco de muitas escolas, que acreditaram ser a autonomia um desencontro em que a indisciplina e a falta de limites se estabeleceram. $\mathrm{Na}$ autonomia, as regras são bastante legitimadas pelos sujeitos porque estes se tornam responsáveis pelo contrato que estabeleceram. São obedientes, portanto, mas não cegamente, porque acreditam na necessidade de que as regras sirvam para o bem de cada um e de todos os possiveis contratantes. Outro equívoco é também comum: se a autonomia é a moral do bem, a heteronomia é a moral do mal. Dessa disparidade decorre a interpretação de que os comportamentos inadequados de alguns alunos, na maioria das vezes heterônomos, sejam maldades, quando são apenas condutas não legitimadas por acordos que comumente se impõem às crianças, porque se acredita que assim seja melhor fazê-lo e por não se considerar o que as escolas tendem, de fato, a esquecer: os sentimentos ou a energia que levam a tais ações.

Agora vejamos: se seguirmos os passos de Piaget (1994), poderemos encontrar em suas pesquisas um postulado interacionista que tende a pensar a moral como uma indissociabilidade entre razão e energia. Segundo ele, a razão é imprescindível à moral porque dispõe para essa última a capacidade de refletir sobre suas direções.

Nesse sentido, a razão pressupõe uma coordenação de ações em um outro plano que não seja apenas perceptivo, mas que tenha operação. Para Piaget, operar significa tal coordenação de ações em plano representativo, em plano de pensamento, quando há uma perspectiva de reversibilidade e essa última compõe uma chave para entendermos, enfim, a primeira necessidade para a moral.

Uma ação reversível, segundo Piaget, é um ir e vir, uma transformação de estados, com volta ao estado inicial em que algo se conserve. Dessa forma, entendemos a necessidade da razão. Essa qualidade humana pressupõe tal estado reversível e, portanto, pensar sobre o ponto de vista do outro significa sair do seu próprio ponto de vista e considerar o do outro, entendendo suas diferenças de modo a compensá-las, sem perder de vista nem as suas razões nem as do outro.

A segunda chave que nos permite pensar a moral, considerando a cognição, é que 
aquele que contrapõe as diferenças, constatando-as e coordenando-as, é capaz de fazer escolhas. Essas últimas deliberam uma condição natural de liberdade para a tomada de decisão que, por sua vez, implica uma característica notadamente humana: a responsabilidade. Digamos que um sujeito não aja com responsabilidade; logo, diremos que está fora de si.

Assim, quando uma ação se torna moral, é caracterizada como evoluída, do ponto de vista de que se supera uma ação primitiva, incapaz de pensar em mais do que uma única possibilidade de se resolverem os problemas. Essa ação, por sinal, freqüentemente se limita às formas violentas.

Agir com responsabilidade indica a existência de uma tomada de consciência (ao menos, dos processos vividos) de suas ações. A consciência supõe, na verdade, a existência de uma faculdade moral que nos permite aprovar ou desaprovar algo. Significa dizer que é, propriamente, tomar consciência de se ter agido em conformidade ou de forma contrária às suas ordens (Smith, 1999).

Agora pensemos: se a razão fosse a única determinante das atitudes morais presentes na conduta humana, como explicar a existência de sujeitos altamente inteligentes, capazes de levantar hipóteses e pensar sobre todas as possibilidades, mas nada morais? Nem Freud, cujas teses revolucionam as teorias que estudam o homem e, dessa forma, torna-se menos idealista que Piaget sobre a possibilidade do agir moral, nem esse último poderiam desconsiderar tal aspecto. Essa é a maior contribuição de Piaget. Porém, seu modelo é todo um esforço por estudar a gênese do conhecimento humano e, portanto, a regularidade das condutas humanas, que são compostas sempre pelos dois aspectos: inteligência e afetividade. Por isso, ressalta o próprio sujeito como agente. Toda sua obra revela a ação do sujeito sobre o que entende por objeto e mesmo as reações desse último são estudadas diante das projeções que procedem do sujeito. As relações estabelecidas entre sujeito e objeto (considerando aqui, pessoas, idéias e objetos materiais, como Piaget pretendia) são constituídas de energia, de afetividade. Nessas relações, projetam-se os investimentos afetivos, revelando os valores que vão se formando na relação com o outro.

Nesse sentido, a ação moral, ou mesmo a emissão de um juízo, requer um sentido de aprovação da conduta ou do julgamento que se estabelece. Necessariamente, essa aprovação estará ligada à razão e aos afetos.

Piaget (1994) intuiria que haveria mais uma variável a ser considerada nas condutas humanas. Ele alerta para o fato de que suas pesquisas estariam se aprofundando em algo que é passível de lógica e de uma verificação empírica. A nosso ver, tal autor nos aponta um pressuposto imprescindivel para os estudos da moral: quando insistentemente anunciava a necessidade de considerar razão e energia, e mesmo ao traçar uma gênese para a afetividade ainda que ligada indissociavelmente às estruturas cognitivas, Piaget anunciava a convergência entre esses dois aspectos do psiquismo que estariam presentes na moral. Em outras palavras, a evolução cognitiva e afetiva do desenvolvimento humano converge na formação de uma personalidade em que os valores de solidariedade, por exemplo, estejam legitimados pelo sujeito (Piaget, 1920; 1962).

Sem nos distanciarmos do referencial piagetiano, que é foco para entendimento de uma pesquisa cujo pressuposto é a educação moral, é preciso que nos atentemos a considerar que a Psicologia Moral tem, a partir das idéias de Piaget com outros autores, a evidência dos afetos como variáveis imprescindíveis para uma ação moral. Não obstante, o cotidiano nos dá mostras de que saber qual o dever a cumprir não impede um sujeito de agir mal. Há uma energia que move, uma necessidade de satisfação pessoal a ser considerada.

As pesquisas de Gilligan (1982) evidenciam a existência desses últimos interferindo na formulação de um juízo ou na ação moral. Tal autora defende que será preciso enxergar as contribuições desse campo afetivo, que conso- 
lidam uma nova dimensão de pensar a moral: o cuidado.

Ora, o leitor deve ter percebido que estamos tratando não apenas da formação moral de maneira geral, mas da construção da personalidade moral. Portanto, tratamos de aspectos muito mais profundos do psiquismo humano. Isso porque "pensar a moralidade dentro do quadro da personalidade representa uma das perspectivas mais promissoras que hoje temos" (La Taille, 1998, p.13), já que nos leva a compreender

sua complexidade, na qual certamente entram fatores relacionados a hábitos, juízos, pressões inconscientes, sentimentos diversos [...], só que de forma integrada, com os fatores interagindo uns com os outros" (1998, p.15).

0 que nos leva ao querer fazer é a questão que evidenciamos ao pensar sobre esse caráter afetivo da moral. Nesse sentido, quando simpatizamos com uma ação, é porque consideramos que esta atende a uma regra geral estabelecida internamente, que depende das representações que temos de nós mesmos, construídas em nossas relações com o meio (La Taille, 2002).

$\mathrm{Na}$ verdade, o que pretendemos destacar é que as representações de si são sempre valorativas - ora positivas, ora negativas - e só são construídas a partir do que sentimos em nossas relações conosco e com os outros, ou seja, da carga afetiva que projetamos nos objetos, aos quais assim atribuimos um valor (Piaget, 1962).

Podemos dizer, então, que o valor de algo ou alguém é formado pela projeção de sentimentos que emitimos. Estamos tratando de algo que necessita de um sistema de significações que precisam estar centradas na identidade do sujeito, para que ele possa, a partir desses sentimentos, estar disposto à realização de uma ação moral.

0 problema que se coloca no momento é de fato não mais responder o que as pessoas precisam para ser morais, mas identificar os caminhos para que essas estruturas cognitivas e afetivas, ligadas a representações de si, possam ser construídas. Em outras palavras, o que fazer para favorecer a construção de "personalidades morais", cujos valores (morais, é claro) estejam centrados na identidade do sujeito?

Ora, estamos chegando, afinal, às disposições do caráter que ampliam a moral porque superam apenas a condição de deveres e direitos e nos permitem constatar seu campo afetivo: as virtudes ou o que poderiamos apenas resumir como "estar disposto a".

Uma virtude é uma força que age ou que pode agir (Comte-Sponville, 1995); há nela um caráter espontâneo, portanto, ligado às disposições próprias. É verdade que a virtude consiste na conformidade com a razão, como causa e princípio da aprovação ou desaprovação, diria Smith (1999). Porém, segundo esse autor, é evidente que o caráter da virtude deve ser atribuído aos afetos, porque deles se origina a força que demanda uma disposição usual e costumeira do espírito.

Tal afirmação significa que há no homem um sentido de realização, um estar voltado para agir em prol de si mesmo, superandose, comum a todos os homens, uma procura constante e uniforme de buscar o bem, a felicidade (Aristóteles, 1996).

Se assim é, uma virtude constitui, primeiramente, o equilíbrio entre o bem para si e o bem para o outro. Dessa forma, ser generoso requer uma disposição de caráter que não exija algo em troca; porque, a princípio, a ação já é disponivel e pressupõe que, ao sujeito que age, não lhe causa mal algum. Há, portanto, um ponto a mais a se discutir. Dar ao outro o que lhe falta e não, necessariamente, o que lhe é de direito é o caráter magnânimo da virtude.

A virtude constitui mais do que um querer moral, estando relacionada a um conjunto de representações de si, um autoconceito que cada um tem para não exigir apenas o que pode ser imediato, o que pode estar ligado a direitos e deveres. Em outras palavras, para ser 
virtuoso é preciso estar bem consigo mesmo, é necessária uma representação equilibrada de si, do ponto de vista das disposições para ser solidário, para ser tolerante, sem nenhuma exigência como retorno (La Taille, 2002).

Dessa forma, podemos ir adiante. Segundo Aristóteles, as virtudes não são capacidades inatas, mas adquiridas por meio do exercício. Não se trata de um processo de ensinar virtudes sob o ponto de vista pedagógico, mas de um constante favorecimento para que elas possam ser exercitadas e tornar-se parte das condutas humanas (Berkowitz, 1996).

0 desenvolvimento do caráter e, podemos dizer, da personalidade moral, que abrange as qualidades precursoras da moral humana, encontra na construção das virtudes o caminho propício ao seu favorecimento (La Taille, 2000).

Assim, será necessário pensar: quais tipos de relações são propícios à formação virtuosa de nossos alunos? 0 que acontece na sala de aula daquela professora de quem emprestamos nossa segunda indagação, no início de nossas discussões, para que seus alunos resolvam os problemas que têm com os outros, digase, tão comuns ou normais do ponto de vista das relações e do desenvolvimento humano, como violência física ou verbal?

Em meio a tais discussões que nos propusemos a apresentar, voltemos ao referencial piagetiano do qual tratávamos. Retornamos a Piaget, não porque haja em sua teoria um modelo pedagógico a seguir. Piaget apontou em seus estudos um pressuposto necessário a qualquer evolução moral. Se bem entendemos, depois de termos realizado toda uma trajetória por compreender, mesmo que resumidamente, as novas pesquisas sobre o desenvolvimento moral e a formação das personalidades morais e, ainda, que tenhamos ido um pouco além do modelo de heteronomia e autonomia piagetianos quando distinguimos a necessidade de elucidar que uma ação moral depende dos valores integrados à identidade do sujeito e, portanto, das representações que ele tem de si, ainda assim, Piaget nos dá pistas para empreendermos uma atmosfera na qual a solidariedade, a tolerância e outras tantas virtudes possam ser construídas. Qual é o remédio? Piaget responde a essa pergunta com uma resposta que nos parece bastante eficaz na edificação de uma "pedagogia das virtudes”: a cooperação (Piaget, 1998).

A cooperação, no sentido piagetiano do termo, implica a descentração de pontos de vista, o "operar com" (Menin, 1996). Do ponto de vista cognitivo e moral, como pensou Piaget, a cooperação se destaca como um instrumento eficaz para a evolução moral porque pressupõe a passagem de um único ponto de vista para a coordenação de vários. Tal passagem, em plano mental, só é possível quando quem pensa for primeiramente sujeito de suas ações. Piaget prescrevia que a ação do próprio sujeito é que faz com que ele conheça os objetos. Dessa forma, pensar sobre os conflitos e coordenar as variáveis que os compõem só é possivel quando esse pensar é realizado pelos sujeitos envolvidos.

Contudo, sob o ponto de vista das relações interpessoais, a cooperação atinge uma abrangência ainda maior para a conquista da moral autônoma. Para Piaget, a cooperação é fruto do sentimento de respeito mútuo, só possivel em posições de igualdade entre os sujeitos. Piaget deixou-nos clara a pertinência da relação entre pares, dizendo o quanto são privilegiadas em possibilidades de evolução moral. Entre iguais, entre as próprias crianças, elas experimentam resolver seus conflitos e suas dúvidas sem o peso de qualquer espécie de obediência. Ao propor o respeito mútuo, Piaget se referia também às relações com os adultos. 0 respeito mútuo entre uma criança e um adulto pressupõe a diminuição de qualquer autoridade.

Temos encontrado outra interpretação equivocada nas escolas: ao agir dessa forma, não significa que estaremos deixando de representar a autoridade que somos, mas como aqueles que superaram ou que deveriam ter superado a heteronomia. Significa que nossas ações estarão longe de se pautarem em castigos, punições ou mensagens de solução que freqüen- 
temente emitimos, com nossos famosos discursos morais (lições) e permitirão que as crianças possam tomar consciência por si de suas faltas, não deixando que prospere o "laissez faire".

Nesse sentido, a relação com a autoridade deixa de ser uma relação de subserviência; ou, em seu extremo, uma relação de paternalismo para atingir seu caráter de confiança. Dessa forma, se a cooperação proposta por Piaget se baseia num sentimento de respeito, é também elucidado seu lado afetivo.

Por ocasião de uma pesquisa empírica, tais relações tomaram boa parte de nosso entusiasmo ao compreendermos como podemos favorecer a formação de sujeitos mais virtuosos.

\section{Uma pesquisa empírica: a construção da solidariedade em ambientes escolares}

Tolerância, respeito, justiça, coragem, amizade, solidariedade são virtudes necessárias à experiência humana da convivência. Uma delas nos demanda um caráter especial: o sair de si e contemplar o outro em sua condição, também humana, demanda um gesto de acolhida, de doar-se. Estamos falando da solidariedade, que foi escolhida como virtude para ser estudada em nossa pesquisa.

Discutindo sobre como as pessoas podem construir a solidariedade, baseando-se em pressupostos filosóficos e psicológicos, que garantem que tal virtude é construída dentro de cada pessoa, a qual elabora suas próprias estruturas e representações da realidade na interação com o meio, nossa pesquisa buscou compreender a influência das relações vividas na escola nessa formação. Nosso problema consistia, portanto, em constatar se crianças, advindas de tipos de relações diferentes, teriam também julgamentos de solidariedade divergentes.

Para tal, foram investigados, comparativamente, os julgamentos de crianças de ambos os sexos, na faixa etária de 6 a 7 anos, provenientes de duas redes de educação municipal, de classe média baixa. Foram sorteadas, de forma aleatória, 23 crianças, igualmente distribuidas entre meninos e meninas, de cada tipo de ambiente: A - escolhido por não apresentar nenhuma metodologia de trabalho específica; e B - em que as crianças são advindas de classes nas quais seus professores aplicam um programa de educação infantil, baseado em pressupostos piagetianos, Programa de Educação Infantil e Ensino Fundamental - PROEPRE. Os dois grupos estudados foram chamados de ambiente A, caracterizado por relações autoritárias; e B, por relações de cooperação, como veremos em nossos estudos.

Para constatar aquele pressuposto de que as virtudes são construídas, quando se considera toda a dimensão humana, em seus aspectos morais, cognitivos e afetivos, três estudos foram realizados.

No primeiro deles, utilizou-se da aplicação das provas de diagnóstico do comportamento operatório de Jean Piaget, no intuito de verificar um paralelo entre as estruturas cognitivas e morais dos sujeitos.

No entanto, se a inteligência pode ser considerada como necessária, mas não suficiente do ponto de vista da evolução moral, também buscamos verificar se haveria aspectos do campo socioafetivo que possibilitariam diferenças no julgamento das crianças. Para tal, utilizamos também uma ficha de observação de como se davam as relações entre professora e alunos e entre as próprias crianças, o que nos permitiu caracterizar os ambientes como coercitivos ou cooperativos. Essa ficha de observação foi elaborada por nós a partir dos estudos de Luckjanenko (1995) e caracterizou nosso segundo estudo.

No terceiro estudo, além desses instrumentos para a maior evidência do que pensavam as crianças, foram criados ou adaptados quatro dilemas morais, contados a elas como histórias em que poderiam decidir pela ação solidária ou não. Esses dilemas foram divididos em dois blocos, que atenderam a dois requisitos da pesquisa: constatar a solidariedade, quando da relação entre pares; e a solidarieda- 
de, quando na presença de uma autoridade que não a julgue necessária. seguintes:

Os dilemas utilizados por nós foram os

1 - João é um garotinho de seis anos que gosta muito de pipas. Ele as confecciona muito bem e tem muita habilidade para soltálas. Na escola de João, haveria um concurso para escolher a pipa mais bonita e o vencedor ganharia um grande prêmio. Ele quis muito participar. No dia do concurso, lá estava João fazendo sua pipa, quando se aproximou dele um garoto de sua idade, desesperado, pois a pipa dele havia sido rasgada. Esse menino também estava participando do concurso e, então, pede a João que lhe empreste um pedaço de papel. João olha bem para a pipa do menino e nota que ela é muito bonita e que ele pode ganhar o concurso. João queria muito ganhar o concurso. 0 que você acha que é melhor João fazer?

2 - Ana é uma garota de seis anos. A casa em que ela mora fica em uma rua com muitas árvores altas e frondosas, nas quais ela adora subir, principalmente na mais alta delas. Ela sobe nela como ninguém! Um dia, ao descer de uma árvore muito alta, Ana escorrega e cai, mas não se machuca. Porém, seu pai, que a havia visto cair, fica muito preocupado com ela e lhe pede que prometa nunca mais subir em árvores. Ana, então, promete-lhe. Nesse mesmo dia, um pouco mais tarde, Ana e seus amigos encontram Patricia, que está muito aflita, pois seu gatinho subiu numa das árvores mais altas da rua e não consegue descer. Ana é a única da turma que sabe subir naquela árvore e pode resgatar o gatinho de Patrícia. No entanto, ela se lembra da promessa que fez a seu pai. 0 que você acha que é melhor Ana fazer? ${ }^{1}$

3 - ( $1^{\text {a }}$ parte) Júlio é um garotinho de seis anos de idade. Na escola em que ele estuda, há um parque com poucos brinquedos e como há várias classes na escola, cada uma tem direito a brincar no parque uma vez por semana. Aquele era o dia da classe de Júlio brincar no parque. Ele estava muito feliz por isso. Se ele perdesse o dia de brincar no parque, só na próxima semana poderia brincar. $\mathrm{Na}$ hora do recreio, depois que Júlio tomou o lanche, chegou o momento tão esperado. Quando Júlio caminhava para o parque, um garotinho de sua idade o chamou. Ele parecia muito triste, pois estava sozinho e não tinha com quem brincar, estava com a perna engessada e não podia sair do lugar. 0 garotinho, então, pede a Júlio que fique brincando com ele naquele dia. 0 que é melhor Júlio fazer? ( $2^{\text {a }}$ parte) Quando Júlio estava indo para o parque, parou para ouvir sua professora, que lembrou: "Júlio, hoje é dia da nossa classe brincar no parque. Você precisa permanecer lá com seus amigos da classe”. E agora, o que é melhor Júlio fazer?

\section{Os resultados encontrados}

Os resultados a que chegamos demonstram a existência de uma evolução na disposição dos sujeitos para serem solidários, ligada a uma perspectiva de vivenciarem as experiências de respeito mútuo, de reciprocidade e da possibilidade de manifestarem seus sentimentos.

Comecemos apresentando os resultados que atenderam a nosso objetivo de constatar o desenvolvimento cognitivo de nossos sujeitos.

\section{Primeiro estudo}

Utilizamos as provas de diagnóstico do comportamento operatório que se referem às noções de conservação de quantidades discretas, do líquido e da massa, às noções de classificação e seriação operatórias.

Constatamos uma grande diferença, em termos dos aspectos cognitivos, na evolução dos sujeitos dos dois ambientes. Quando aplicamos as provas de diagnóstico do comportamento operatório, encontramos, no estágio pré-operatório,

1. Adaptação do dilema descrito in Turiel, E.; Enesco, I.; Linaza, Y. (1989). 
30,43\% dos sujeitos do ambiente A, caracterizado como um ambiente coercitivo, e nenhum sujeito do ambiente B, caracterizado como um ambiente cooperativo. Em transição, encontramos 69,57\% dos sujeitos do ambiente A e 56,52\% dos sujeitos do ambiente $B$, embora os níveis de transição oscilassem nesse último ambiente, numa pontuação mais elevada, próxima à do estágio operatório. 0 mais relevante é que, dentre a amostra que tivemos, não encontramos sujeitos operatórios no ambiente A, enquanto 43,48\% dos sujeitos do ambiente $\mathrm{B}$ demonstraram um pensamento reversível.

Tal dado nos leva a inferir quanto à necessidade de um pensamento operatório para considerar o outro, pois encontramos uma similaridade entre esse aspecto do psiquismo e o desenvolvimento moral de nossos sujeitos, como veremos a seguir.

Em nenhum momento, porém, podemos afirmar que esta se constitua em uma condição suficiente, principalmente para a solidariedade que, como virtude, perpassa por domínios cognitivos e afetivos. lsso porque encontramos, também entre os sujeitos do ambiente $A$ que não apresentaram um pensamento operatório, julgamentos de solidariedade. Como explicar? Tal fato nos leva a considerar outros aspectos, ligados às questões socioafetivas, que poderão explicar juízos mais elevados entre os sujeitos do ambiente cooperativo.

Nos quatro dilemas apresentados aos 46 sujeitos participantes da pesquisa, suas respostas nos permitiram concluir que as crianças que vivenciam experiências de escolhas, de tomadas de decisão e de relações de confiança com a autoridade estão muito mais próximas, ao menos em seus juízos, de evidenciarem a solidariedade. Tal conclusão é ainda mais clara quando observamos as relações interpessoais que se faziam presentes nas salas de aula dos dois ambientes.

\section{Segundo estudo}

Para compor tal observação das relações interpessoais, utilizamos uma ficha de observação que nos permitiu caracterizar os dois tipos de ambientes. As observações foram distribuídas em questões que destacaram a relação professor-aluno (por exemplo, se havia punições, gritos, ameaças...), a relação entre os pares (se havia trabalhos em grupos, oportunidades de escolhas, se os alunos utilizavam argumentos verbais para resolver seus conflitos...) e quanto à estruturação do dia de aula (se havia regras formuladas pelo grupo, se a disposição física da sala permitia a interação entre os pares...). Para uma análise mais clara, atribuímos pontos que nos permitiram pensar esses ambientes em níveis de cooperação e seu contrário. Foram atribuidos pontos de 1 a 3 para cada item, numa escala crescente de propostas mais coercitivas a propostas de maior cooperação.

Encontramos, conforme tal classificação, o ambiente $A$ com 76 pontos e o ambiente B com 162 pontos, o que nos permitiu considerálo como um ambiente altamente cooperativo, a partir da seguinte escala, expressa no Quadro 1.

Pela somatória dos pontos, pudemos definir o ambiente A como um ambiente coerci-

Quadro 1. Atribuição de pontuação aos tipos de ambientes sociomorais.

\begin{tabular}{|l|l|}
\hline 0 a 107 pontos & Ambiente coercitivo \\
\hline 108 a 140 pontos & Ambiente propenso à cooperação \\
\hline 140 a 162 pontos & Ambiente cooperativo \\
\hline
\end{tabular}

tivo, cujas relações são baseadas num tipo de respeito unilateral, em que a autoridade impõe as regras, emite julgamentos sobre as crianças e se utiliza de castigos e punições para seu desenvolvimento moral. Em contrapartida, o ambiente B, caracterizado pelas experiências de reciprocidade, de respeito mútuo, em que a autoridade divide com os alunos a possibilidade de formulação de regras e sanciona seus comportamentos de forma a fazê-los compreender o valor das normas estipuladas pelo grupo, é então distinguido por nós como ambiente cooperativo ${ }^{2}$.

Nosso terceiro estudo responde à problemática que evidenciamos nessa pesquisa: haveria diferenças no julgamento de situações morais de solidariedade de crianças advindas de ambientes morais diferentes?

2. A ficha de observação encontra-se publicada em Tognetta, 2003, p. 192. 


\section{Terceiro estudo}

De forma sucinta, apresentamos um resumo dos dados encontrados para cada dilema que foi apresentado aos sujeitos. São dilemas que apresentam situações em que a solidariedade, por decisão do sujeito, pode ou não acontecer.

As respostas de nossas crianças foram organizadas em categorias e, depois, separadas em níveis, que nos permitiram destacar a evolução desde a ausência da solidariedade até sua presença mais sentida.

\section{Parte 1 - A solidariedade entre pares}

Comecemos por aqueles dilemas em que não há o peso maior de um sobre o outro, entre pares, "implicando a afirmação de que as respostas ou não de solidariedade estarão baseadas no princípio do auto-reconhecimento" (Tognetta, 2003). São dilemas que excluem qualquer forma de autoridade.

0 primeiro diz respeito a um personagem que gostava muito de pipas e era um ótimo confeccionador desse brinquedo. la participar de um concurso, concorrendo a um grande prêmio, o qual desejava muito ganhar, e tinha que decidir entre emprestar um pedaço de papel a um outro garoto, que poderia vencer o concurso, ou não. "0 que seria melhor fazer?", foi a pergunta que fizemos a nossos entrevistados.

0 terceiro dilema, outro entre pares, como vimos, apresenta a história de um garoto que gostava muito de ir ao parque, no entanto, em sua escola não havia um grande número de brinquedos, o que fazia com que cada dia da semana fosse reservado à presença de uma das salas no tão desejado local. Ele tem de decidir entre ir ao parque ou ficar com um garoto que está com a perna engessada e lhe pede que brinque com ele. Novamente, a pergunta que se faz é como seria melhor o personagem proceder.

A partir desses dilemas, depois de categorizarmos as respostas de nossas crianças, encontramos um fato bastante importante. Em ambos os ambientes, pudemos constatar que as respostas, distribuídas em níveis, reforçam nossa afirmação de que é preciso um ambiente cujas relações sejam cooperativas e cujos sentimentos sejam manifestados para que se evidencie a solidariedade.

Como dissemos, distribuímos as categorias encontradas para cada dilema em níveis: o primeiro deles engloba as categorias cuja característica é a ausência total de solidariedade; o segundo, aquelas que refletem uma certa admissão da solidariedade ou a determinação de condições para que ela aconteça. No terceiro nível, mais evoluido, consideramos as categorias que indicam a ação solidária ligada ao dever ou à reciprocidade, supondo que os juizos emitidos podem ser frutos de experiências interiorizadas das falas dos adultos e, por esse motivo, ainda ocupam um nível anterior ao último, quando nos parece clara a decisão pela solidariedade. No último nível, portanto, consideramos que a ação solidária é determinada pela disposição própria do sujeito, que não se sente ofendido nem apresenta restrições para a solidariedade.

Apresentamos, a seguir, as categorias que encontramos nas respostas das crianças entrevistadas. Para o dilema da pipa, foram as seguintes:

Vejamos os resultados obtidos: nenhuma resposta das crianças advindas do ambiente $A$ foi encontrada no quarto nível para o di-

Quadro 2. Distribuição das categorias do dilema 1

\begin{tabular}{|c|c|l|}
\hline Nivel & \multicolumn{2}{c|}{ Categorias } \\
\hline I & 1 & 0s sujeitos não compreendem o dilema e não sabem responder. \\
\cline { 2 - 3 } & 2 & 0 bem a si próprio está acima da solidariedade. \\
\hline II & 3 & A razão da solidariedade está nas conseqüências materiais. \\
\hline III & 4 & A ação solidária como dever. \\
\cline { 2 - 3 } & 5 & A ação solidária ligada à reciprocidade. \\
\hline IV & 6 & A disposição para a solidariedade. \\
\hline
\end{tabular}

lema da pipa, enquanto obtivemos sete respostas, nesse nível, das crianças do ambiente B. Esse é o dado mais significativo. Outro dado, ainda nesse dilema, é que 76,19\% das respostas classificadas no nível 1 foram apresentadas por crianças do ambiente $A$, contra $23,81 \%$ das crianças do ambiente B. 
Dá um pedaço de papel para ela [...]. Ué, ela ganhou? Ela não tem culpa, não tem culpa, ganhou, ganhou, diria ALU, uma criança do ambiente $B$, afirmando que a ação solidária deveria acontecer. Essa é uma resposta clara de nivel 4 ( $6^{\text {a }}$ categoria), porque indica que mesmo com as nossas contra-argumentações sobre como ficaria nossa personagem principal, a qual queria tanto ganhar o concurso, vendo a outra garota ganhá-lo, continua evidenciando a disposição pela solidariedade sem nenhuma perda.

Para tantos outros, a ação solidária não aconteceria porque: Ele ia ficar sem prêmio [...]. É melhor não emprestar, como afirmava LEO, do ambiente A. Assim como tantas outras crianças, acostumadas ao individualismo, ao silêncio absoluto, LEO compreende que um desejo próprio deve ser maior que a ação solidária.

Quanto ao dilema 3, que apresentava a história do garoto com a perna engessada,

Quadro 3. Distribuição das categorias do dilema 3

\begin{tabular}{|c|c|l|}
\hline Nivel & \multicolumn{2}{|c|}{ Categorias } \\
\hline I & 1 & 0 bem a si próprio está acima da solidariedade. \\
\hline \multirow{2}{*}{ ॥ } & 2 & Admite-se a solidariedade, embora não haja disposição própria. \\
\cline { 2 - 4 } & 3 & A solidariedade dependendo de determinadas condicōes. \\
\hline \multirow{2}{*}{ III } & 4 & A ação solidária como dever. \\
\cline { 2 - 4 } & 5 & A ação solidária ligada à reciprocidade. \\
\hline \multirow{2}{*}{ IV } & 6 & Tentativas para conciliar o desejo próprio e a ação solidária. \\
\cline { 2 - 4 } & 7 & A disposição para a solidariedade. \\
\hline
\end{tabular}

foram encontradas as seguintes categorias:

Para esse dilema do garoto da perna engessada, temos dados semelhantes: no nível 4 , mais evoluído, temos $78,26 \%$ das respostas entre as crianças do ambiente $B$ e $21,74 \%$ das respostas entre as crianças do ambiente $A$, enquanto que para o primeiro nível, menos evoluído, em que a ausência da solidariedade se constata, 92,86\% das respostas foram apresentadas pelas crianças do ambiente $A$, contra $7,14 \%$ de respostas do ambiente $B$.

Para VIN, do ambiente B: Então, mas se ele não fosse hoje, só depois de uma semana. Quando contra-argumentamos afirmando que o garoto gostava muito de brincar no parque, VIN nos responde: Ah, mas ele brinca com o menino, ele tá com a perna quebrada.
Constatamos pelas respostas de VIN que não há problemas quanto às disposições para ser solidário. Talvez a experiência do parque conte muito para as crianças do ambiente $\mathrm{B}$, acostumadas a momentos de espontaneidade, que se distinguem pela não intervenção direta do adulto. Um dado relevante é que, em nossas observações, pudemos notar que às crianças do ambiente $A$, das relações ditas autoritárias, são reservados apenas quinze minutos restantes do recreio, por dia, para o parque. A tal dado, acrescente-se a falta das experiências simbólicas das propostas de faz-de-conta, tão importantes ao desenvolvimento das crianças, quando podem se relacionar diretamente entre seus pares, além de consigo mesmo.

Dessa forma, em contrapartida, MARC, do ambiente $A$, sugere que o personagem vá ao parque porque gosta muito. Quando questionado sobre como ficaria o garoto com a perna engessada, constatamos que a solidariedade fere um desejo próprio de MARC: Chama outro menino para brincar com ele. Quando questionamos: Chamar outro menino? E se nenhum outro menino quisesse brincar com ele?, MARC nos responde: Aí ele não brinca com ninguém.

Quando destacamos a presença da autoridade no processo de resolução do dilema, os resultados que obtivemos não foram muito diferentes.

\section{Parte 2 - Solidariedade e enfrentamento da autoridade}

0 primeiro dilema que apresentamos às crianças conta a história de uma personagem que adorava subir em árvores e o fazia como ninguém. Certo dia, quando caiu do alto de uma árvore, o pai lhe fez prometer que nunca mais subiria. Ela teria que decidir entre subir novamente na árvore para salvar um gatinho ou respeitar a promessa. "0 que seria melhor fazer?", foi a pergunta que fizemos às crianças.

Novamente, suas respostas foram categorizadas e encontrados os quatro níveis já distinguidos anteriormente. 
A seguir, vejamos as categorias encontradas nas respostas das crianças para o dilema do gatinho. Notemos que, como nos demais dilemas, essas categorias são apresentadas numa evolução, desde a ausência total da solidariedade, agora pela obediência, pelo medo do castigo, até quando há uma disposição tão certa para tal ação que, mesmo os contratos, no caso em questão, com o pai, precisam ser quebrados porque há uma necessidade maior a ser cumprida ou, então, quando a confiança predomina sobre o medo da autoridade.

No primeiro nível, como nos dilemas anteriores, a solidariedade não é manifestada, em virtude da determinação da autoridade. $71,43 \%$ das respostas desse nível foram dadas

Quadro 4. Distribuição das categorias do dilema 3

\begin{tabular}{|c|c|c|}
\hline Nivel & & Categorias \\
\hline \multirow{3}{*}{ I } & 1 & A desobediência traz consequêências desagradáveis ao sujeitto. \\
\hline & 2 & A decisāo é tomada tendo em vista a ordem do adulto. \\
\hline & 3 & A solidariedade é inibida pelo compromisso com a autoridade. \\
\hline ॥ & 4 & Cálculo de risco (se a autoridade não estiver presente). \\
\hline III & 5 & Altermativas para conciliar a obediência à autoridade com a ação solidária. \\
\hline \multirow[b]{2}{*}{ IV } & 6 & A confiança determina a açăo solidária. \\
\hline & 7 & A ação solidária exige a quebra do contrato. \\
\hline
\end{tabular}

por sujeitos do ambiente A e 28,57\% por sujeitos do ambiente B. Para esses sujeitos, "não subir, porque ele tem que obedecer ao pai" (LUI, ambiente A) é resposta comum.

No segundo nível, encontramos as categorias que admitem a solidariedade, porém, por ações contestáveis, mentem ou tapeiam a autoridade. Para EVE, do ambiente A:

"Ela sobe escondido".

Mas ela prometeu para o pai dela que não iria subir!

"Ela fala que vai brincar na esquina e sobe na árvore."

Mas, a Ana pode subir?

"Pode, sem o pai dela saber."

Num nível mais evoluido, as categorias expressam as tentativas das crianças de conciliarem a ação solidária e a obediência ao contrato estabelecido com a autoridade. As crianças sugerem pegar uma vassoura para retirar o gato da árvore, chamar bombeiros e tantas outras estra- tégias que nos fazem acreditar em sua busca por não desobedecer à ordem do pai, mas cumprir com a ação solidária. Tais respostas encontram um equilíbrio entre as crianças dos dois ambientes: $29,54 \%$ do ambiente A e 34,04\% do ambiente B. Um exemplo da busca por alternativas é a resposta de CAM do ambiente $B$ :

"Cata uma escada."

Ai, mas não tem escada que pegue aquele gato, de tão alta que é aquela árvore, CAM.

"Mas aí compra três escadas, daí gruda, daí dá."

Porém, constatamos que nas duas categorias distintas do nível 4 (a confiança de que a autoridade permitirá que a ação aconteça, devido à exigência de se tomar uma atitude que atenue o sofrimento do dono do gato ou a quebra do contrato estabelecido com o pai, porque um princípio maior está sendo ferido) há uma grande diferença entre os dois ambientes.

Nesse último nível, nenhuma resposta das crianças do ambiente A foi encontrada, enquanto que houve 12 respostas das crianças do ambiente B. Elas acreditam na força de sua relação de confiança com a autoridade, mesmo quando é necessária a quebra do contrato, conforme MAl, também do ambiente B:

"É melhor ela subir e pegar o gatinho e falar: Ô pai, o gatinho subiu lá e eu tive que pegar".

E o que você acha que o pai dela vai fazer?

'Brigar com ela."

É? Mas mesmo assim ela sobe?

"Sobe."

Quando contamos o dilema do garoto que encontra o outro com a perna engessada, destacamos uma segunda parte onde a professora chega bem no momento em que, supostamente, nosso personagem decide ficar com o menino que não podia sair do lugar. A professora, então, diz que ele deve ir para o parque, já que é o dia de sua turma estar lá. Perguntamos, a partir desse fato, o que seria melhor o 
personagem fazer. Como vimos, é nosso quarto dilema. A seguir, apresentamos as categorias encontradas, muito parecidas com aquelas do dilema anterior.

Quadro 5. Distribuição das categorias do dilema 4

\begin{tabular}{|c|c|l|}
\hline Nivel & \multicolumn{3}{|c|}{ Categorias } \\
\hline \multirow{2}{*}{ I } & 1 & A ação solidária não acontece porque fere interesses próprios. \\
\cline { 2 - 4 } & 2 & A decisão é tomada tendo em vista a determinação do adulto. \\
\hline II & 3 & A ação solidária é realizada, burlando a autoridade. \\
\hline III & 4 & Alternativas para concilliar a obediência à autoridade com a açăo solidária. \\
\hline \multirow{2}{*}{ N } & 5 & A confiança determina a açăo solidária. \\
\cline { 2 - 4 } & 6 & A ação solidária exige a quebra do contrato. \\
\hline
\end{tabular}

Vinte e duas respostas das crianças do ambiente A e sete do ambiente B são encontradas no primeiro nível, representando $75,86 \%$ e $24,41 \%$, respectivamente, das respostas assim distinguidas, em que a ação solidária não acontece pela obediência à ordem adulta. Encontramos apenas uma resposta entre as crianças do ambiente A no último nível, em que há a confiança ou a quebra do contrato, enquanto quinze respostas do ambiente $B$ caracterizaram 93,75\% das respostas para esse nível.

Consideramos essas respostas como ações solidárias porque excluem todo elemento de submissão que a autoridade pressupõe. Para Piaget, a relação entre pares contribui para a descentração. Não é por acaso, portanto, que as crianças do ambiente $A$ apresentam tamanha dificuldade em se desvencilhar da obediência cega à autoridade adulta.

Dessa forma, as crianças, advindas de ambientes em que a autoridade do professor não é reduzida ao mínimo possível nas tomadas de decisão e resolução de conflitos interpessoais, apresentam-se muito menos propensas a exercer sua autonomia, não como desobediência, mas com a legitimação da necessidade da solidariedade, demonstrada em seus argumentos e justificativas. Assim responde ALU, do ambiente $B$, ao dilema do garoto com a perna engessada, na presença da professora:

Então a professora falou assim para Júlia: "Júlia, é hora de ir para o parque" e agora, $A L U$, o que é melhor Júlia fazer?
“Falar: professora, eu posso levar a menininha comigo lá no parque? [...] Essa menininha tá com a perna engessada, deixa eu brincar com ela? Ela tá muito sozinha. Aí a professora vai ficar com dó e vai deixar."

As conclusões a que chegamos com a apresentação dos dilemas são claras: o último nível, que apresenta categorias em que a disposição para a solidariedade está presente, foi encontrado com muito mais freqüência nos julgamentos das crianças do ambiente B. Como vimos por essa análise, em dois dos quatro dilemas discutidos não houve respostas das crianças do ambiente $A$ contidas nesse último nível.

Parece-nos relevante destacar um dado fundamental nesse momento em que acabamos de concluir os resultados sobre os quatro dilemas apresentados às crianças: pode parecer ao leitor que as classificamos, portanto, em solidárias ou não solidárias.

Quando utilizamos uma análise estatística, chamada Análise Discriminante, podemos acentuar que, embora nossos resultados comprovassem que a maioria das respostas de níveis considerados superiores, em termos de presença de julgamentos de solidariedade, foi encontrada entre sujeitos do ambiente $B$, não podemos classificá-los dessa forma.

Tal análise estatística consistiu em encontrar uma certa similaridade entre as respostas dos sujeitos de cada ambiente e separá-las em dois grupos distintos, os quais atendessem àquilo que têm em comum, ou seja, verificouse se o sujeito apresentava respostas que faziam parte das características destacadas por seu grupo ou não.

Dessa forma, foi possível predizer que mesmo que a maioria absoluta das respostas dos sujeitos do ambiente A estivesse de acordo com as características coercitivas, havia uma pequena parcela de respostas que se apresentavam mais propensas ao outro grupo. 0 mesmo ocorreu com as respostas dos sujeitos do ambiente $B$, que estavam de acordo com as características de um ambiente cooperativo. 
Esse fato demonstra nossa preocupação em não classificar os sujeitos em solidários ou não, de acordo com o ambiente, significando que a solidariedade depende, também, de outros fatores além do ambiente escolar.

Por outro lado, tais constatações, realizadas em nosso estudo, revelam a importância do tipo de relações estabelecidas na escola. Embora tenhamos apresentado os dados de nossa pesquisa bastante resumidos, destacando apenas os níveis mais diferenciados (quando a solidariedade não é encontrada e quando as disposições para tal virtude se fazem presentes), acreditamos que tais revelações podem confirmar nossas hipóteses de que um ambiente onde as crianças possam se expressar livremente, sem coerções e possam dizer o que sentem, possam decidir e opinar, será mais promissor para a solidariedade.

As discussões, que firmamos no início deste artigo, parecem tomar um sentido mais concreto diante dos dados apresentados: a solidariedade, a tolerância, a justiça e o respeito, que tanto desejamos, dependem de uma construção progressiva do próprio sujeito que age. Parece-nos evidente que as instituições que educam ocupem um papel fundamental nessa formação. Nas palavras de Piaget (1998), não é um tipo de respeito comum por uma regra exterior que cria a solidariedade, mas sim “a colaboração na constituição da regra comum. Tampouco é o respeito coletivo pela palavra adulta que cria a compreensão, mas a discussão e o controle mútuo".

Com tais resultados emitidos e se uma virtude pode ser ensinada "mais pelo exemplo que pelos livros", como diria Comte-Sponville (1995), há esforços de nossa parte em encontrar uma suposta "pedagogia das virtudes". Uma pedagogia que considere tanto a dimensão cognitiva da moral, quanto a sensibilidade necessária para pensar bem como para sentir e, dessa forma, poder encontrar caminhos que permitam evocar os domínios afetivos dessa moral. Uma pedagogia que considere a cooperação como princípio fundamental, conforme pudemos constatar em nossa pesquisa.
Tornou-se evidente, nessas investigações, que a relação de confiança com a autoridade é fundamental na formação de julgamentos por solidariedade. Como vimos, as crianças do ambiente cujas relações eram autoritárias, baseadas em discursos do professor ou em castigos e punições, não julgavam possível que uma ação solidária acontecesse caso a autoridade fosse contrária, uma vez que não tinham a experiência da confiança, do argumentar, do justificar e esperar que o outro as compreendesse.

É possível que a criança que sinta tal relação de confiança, em detrimento de uma relação de obediência e de castigo, sinta vergonha daquilo que causou seu comportamento. Sentindo vergonha, tal criança poderá construir para si o valor de se tornar responsável por suas ações. Caso contrário, se as ações do adulto impuserem uma conduta pela humilhação, não há valor moral que se conserve. A representação de si, que a criança constrói pela humilhação, será sempre de caráter destrutivo (La Taille, 1996).

Quando as crianças experimentam serem tratadas afetivamente, nas relações de cooperação e de confiança, podem construir sua autoestima, o gostar de si, o autoconhecimento, o entender o que sentem e o autocontrole, o saber controlar suas emoções e seus sentimentos.

A esse ponto, o leitor deve estar se perguntando: como, de fato, sabendo das características que compõem a moral, podemos contribuir, como educadores, para a sua formação?

Quando as crianças com as quais trabalhamos têm a possibilidade de pensarem sobre suas ações, de reconstituí-las, ao expressarem o que poderiam ter feito para que um determinado comportamento inadequado não acontecesse, estamos favorecendo a construção das estruturas de pensamento (Mantovani de Assis, 1998). Por outro lado, quando permitimos que as crianças se sintam acolhidas, pelo respeito mútuo, pela disposição do adulto em não as punir e, sim, auxiliá-las a encontrar soluções para seus conflitos, estamos favorecendo tal construção das representações de si mesmo, de que tratamos anteriormente. 
Da mesma forma, quando as crianças se acostumam a expressar o que sentem, suas dores, suas angústias, num conflito entre pares, legitimam uma experiência extremamente relevante do ponto de vista psicológico: aprendem que o que sentem ou pensam é tão importante que precisa ser dito. Quando tratamos de elencar os pressupostos de uma pedagogia das virtudes, estamos certos de sua dimensão afetiva.

Ora, a idéia é a seguinte: digamos que, nesse momento, estamos considerando uma virtude como um valor. E como construímos um valor? Todo valor é uma projeção de sentimentos. Quando permitimos que as crianças experimentem expressar o que sentem, num conflito entre pares, estamos permitindo que se indignem, que sintam raiva. Porém, ao se indignarem, apresentando ao outro as razões de tal indignação, estamos favorecendo que elas possam construir, para si, um gostar de si que não permita que a façam sofrer e, ao mesmo tempo, um respeito pelo outro, porque lhes damos as razões para desaprovar suas ações.

Nesse sentido, o fato de indignar-se permite que se construa o valor do diálogo, da tolerância, do perdão, do arrependimento, da amizade como conseqüência das ações não violentas, que podem ser impedidas quando as transformamos em expressão de sentimentos. Queremos dizer que é preciso permitir a raiva, instigando a criança a encontrar maneiras de expressar o que sente, sem violência.

$\mathrm{Na}$ verdade, as virtudes que desejamos ver estampadas nas ações cotidianas de nossos alunos não são fáceis de serem conquistadas. São disposições internas que precisam ser construídas a cada conflito com o meio, a cada experiência que permita reunir a dimensão moral, cognitiva e afetiva de suas realizações, portanto, com cooperação.

Ao professor, educador em especial, cabe a tarefa de considerar a ampla dimensão do psiquismo humano: se a moral depende da razão, as crianças devem encontrar na escola um ambiente que propicie desafios a sua inteligência, que lhes permita tomar decisões, fazer escolhas, resolver seus conflitos, o que requer participação efetiva na assembléia da qual fazem parte (Mantovani de Assis, 1996). Sim, a sala de aula é uma grande assembléia que resolve, que legisla, estabelecendo, cumprindo e cobrando combinados ou regras (Araújo, 2000).

No entanto, como vimos anteriormente, é preciso ainda que se considere um outro aspecto imprescindível: a afetividade. Talvez essa seja a chave para entender o porquê de a educação ainda se queixar tanto da indisciplina por parte de seus alunos. Quando a escola, ou qualquer instituição que educa, favorece a expressão dos sentimentos, a contraposição aos sentimentos do outro, está permitindo que as crianças construam as representações necessárias para uma ação virtuosa, como pudemos constatar entre as crianças provenientes do ambiente $B$ de nossa pesquisa, acostumadas a fazê-lo.

Diferente do que muitos pensam, trabalhar com a afetividade na escola não significa acarinhar e relevar comportamentos inadequados. 0 carinho ou a atenção que damos às crianças encontram-se na possibilidade de que elas construam sua estima própria e seu autocontrole, regulando suas ações e permitindo que, pelo exercício desse falar de si, possam tornar-se futuramente adultos equilibrados e sensíveis às necessidades do outro.

Digamos que a solidariedade pede empatia com o estado afetivo do outro, mas essa só é conquista de um estado de equilíbrio em si porque tal disposição para uma ação virtuosa acontece quando não se deseja nada em troca. É a superação de si, é estar bem consigo para estar e buscar o bem para os outros.

Necessariamente, uma virtude depende dos sentimentos que são projetados nos objetos, em nosso caso, nos sujeitos que esperam pela ação solidária. Por sua vez, somente um ambiente cooperativo poderá assegurar esses estados de empatia com o outro (Mantovani de Assis, 1996).

Portanto, temos duas condições a observar quanto ao aspecto da criança vir a ser mais solidária: esquecer as queixas de que as pessoas não são boas e considerar que elas possam estar melhores é nossa primeira condição; a segunda é 
nos dispormos também a sermos virtuosos, considerarmo-nos humildes o bastante para enxergarmos o quanto ainda temos a aprender quanto ao psiquismo humano e à construção da moral.
Nosso desejo é que as discussões apresentadas possam tornar-se um fomento para pensar a moral de forma a buscar a maior e melhor realização humana: a felicidade.

\section{Referências bibliográficas}

ARAÚJO, U. Escola, democracia e a construção de personalidades morais. Educação e Pesquisa. São Paulo: Faculdade de Educação/USP, v. 26, n.2, p. 91-107, jul./dez., 2000.

ARISTÓTELES. Ética a Nicomaco. São Paulo: Summus, 1996.

BERKOWITZ, M. W. Educar la persona moral en su totalidad. In: BUXARRAIS, M.; MARTínEZ, M.(Org). Educación en valores y desarrollo moral. Barcelona: Editorial-Gráficas Signo, 1996.

COMTE-SPONVILLE, A. Pequeno tratado das grandes virtudes. São Paulo: Martins Fontes, 1995.

GILLIGAN, C. Uma voz diferente. Rio de Janeiro: Ed. Rosa dos Ventos, 1982.

LA TAILLE, Y. A indisciplina e o sentimento de vergonha. In: AQUINO, J. G. (Org.). Indisciplina na escola: alternativas teóricas e práticas. São Paulo: Summus, 1996.

Prefácio à edição brasileira. In: PUIG, J. M. A construção da personalidade moral. São Paulo: Ática, 1998.

. Para um estudo psicológico das virtudes morais. Educação e Pesquisa. São Paulo, Faculdade de Educação/USP, v. 26, n. 2, p. 109-121, jul./dez., 2000.

Vergonha: a ferida moral. São Paulo: Ed. Vozes, 2002.

LUKJANENKO, M. F. S. P. Um estudo sobre a relação entre o julgamento moral do professor e o ambiente escolar por ele proporcionado. 1995. Dissertação (Mestrado) - Faculdade de Educação, Unicamp, Campinas, 1995.

MANTOVANI DE ASSIS, 0. Inteligência, vida social e afetividade na teoria piagetiana. In: Encontro Nacional de Professores do PROEPRE: Construtivismo e Educação, 12., Anais... Campinas: LPG, FE, Unicamp, 1996.

. A escola e a construção das estruturas da inteligência na criança. In: . Desenvolvimento sustentado: problemas e estratégias. São Paulo: Academia de Ciências do Estado de São Paulo, 1998, p. 351-391.

PIAGET, J. El psicoanálisis y sus relaciones com la psicología del niño. In: DELAHANTY, G. P. (Comp). Piaget y el psicoanálisis. México: Universidade Autonoma Metropolitana, [1920] 1994, p.181-290.

. La logique de l'enfant et l'égocentrisme. Paris: L'École Libératrice, 1931.

. Las relaciones entre la inteligencia y la afectividad en el desarrollo mental del niño. In: DELAHANTY, G. P. (Comp). Piaget y el psicoanálisis. México: Universidade Autonoma Metropolitana, [1962] 1994, p.181-290.

. 0 juízo moral na criança. São Paulo: Summus Editorial, 1994.

. 0 espírito de solidariedade e a colaboração internacional. In: PARRAT-DAYAN, S.; TRYPON, A. Sobre a pedagogia: textos inéditos. São Paulo: Casa do Psicólogo, 1998. 
SMITH, A. Teoria dos sentimentos morais. São Paulo: Martins Fontes, 1999.

TOGNETTA, L. A construção da solidariedade e a educação do sentimento na escola. Campinas: Mercado de Letras/FAPESP, 2003.

Recebido em 19.01.05

Modificado em 22.12.05

Aprovado em 14.02.05

Luciene Regina Paulino Tognetta é doutora pelo Instituto de Psicologia-USP. Membro do Laboratório de Psicologia Genética da Faculdade de Educação da Unicamp e do GEPEM/Unesp.

Orly Zucatto Mantovani de Assis é professora titular da Faculdade de Educação - Unicamp. Coordenadora do Laboratório de Psicologia Genética da Unicamp e Coordenadora do PROEPRE (Programa de Educação Infantil e Ensino Fundamental). 